\title{
Ultrastructural Pathology of Peripheral Nerves in Patients with Diabetic Neuropathy
}

\author{
Soroku Yagihashi and Muneo Matsunaga* \\ The First Department of Pathology and *the Third Department \\ of Internal Medicine, Hirosaki Iniversity School of Medicine, \\ Hirosaki 036
}

\begin{abstract}
Yagihashi, S. and Matsunaga, M. Ultrastructural Pathology of Peripheral Nerves in Patients with Diabetic Neuropathy. Tohoku J. exp. Med., 1979, 129 (4), 357-366 - Sural nerve lesions in patients with clinically manifest diabetic neuropathy were investigated electron microscopically. Myelinated nerve fibers were reduced in all the diabetic patients. Axonal degeneration of both myelinated and unmyelinated nerve fibers was most conspicuous finding in the diabetic sural nerves. Structural changes of the axons were represented by axonal dwindling, depletion of axoplasmic organelles, vacuolarization and an increase in neurofilaments. Accumulation of glycogen-like particles and deposition of electron homogeneous amorphous materials were noted within a few axons. On the other hand, there could also be found degenerative changes of myelin sheaths, various kinds of cytoplasmic inclusion bodies (crystalloid, lamellar inclusion bodies and lipids-like droplets), aggregates of glycogen particles in the Schwann cell cytoplasm and basement membrane hyperplasia of Schwann cells in all the subjects. Furthermore, multiplication and thickening of the basement membrane of vasa nervorum were constant findings of the diabetie sural nerves. The vascular changes, demyelination and axonal degeneration of the cases were not apparently correlated with each other. There was no special relationship between nerve tissue changes and clinical symptoms or laboratory findings. These results indicated that the peripheral nerve lesions in human diabetics were mainly due to metabolic impairment of nerve fibers, accompanying dysmetabolism of Schwann cells and diabetic microangiopathy, and that these changes proceeded independently diabetic neuropathy; ultrastructure; axonal degeneration; demyelination; microangiopathy
\end{abstract}

Although peripheral neuropathy is a very common complication in the diabetic patients, the adequate clarification for the morphological alterations of nerve tissues in the human diabetics has not yet been presented. In an autopsy study on the diabetic patients, Greenbaum et al. (1964) observed degeneration and loss of myelinated nerve fibers and nerve cells in both spinal cord and ganglions and they considered that a neuronal disorder was mainly responsible for the diabetic neuropathy. On the contrary, subsequent light microscopic studies on the diabetic peripheral nerves using a teased nerve fiber method suggested that the dysmetabolism of Schwann cells, resulting in an eminent segmental demyelination,

Received for publication, December 6, 1978. 
was the main cause of diabetic neuropathy (Thomas and Lascelles 1965, 1966; Chopra et al. 1969; Chopra and Fannin 1971).

Recent electron microscopic studies have thrown light to some degree on the pathogenesis of diabetic neuropathy, showing an abundant axonal degeneration of nerve fibers, and it has become to be reemphasized that the diabetic neuropathy should be ascribed to a neuroaxonal disorder induced by metabolic impairment (Bischoff 1973; Brown et al. 1976).

In this study, we attempt to clarify the pathogenesis of human diabetic peripheral neuropathy on the basis of the ultrastructural findings of diabetic sural nerve lesions.

\section{Materials and Methods}

Sural nerve biopsies were undertaken on five male patients with clinically manifest diabetic neuropathy, according to the method of Dyck and Lofgren (1966). The case summaries of the diabetic subjects concerning the diabetic state, neurological symptoms and laboratory findings were shown in Table 1. The diabetic control of the patients was decided by the mean M-values of diurnal blood glucose levels (Goto et al. 1972) in 3-6 months before the performance of the nerve biopsy, and the nerve conduction velocity was represented by the latest estimation until the time of the nerve biopsy.

TABLE 1. Case summaries of five diabetic subjects

Case
No. Age Sex

* Diabetic control is determined by mean M-values evaluated from blood glucose levels (Goto et al. 1972).

$\uparrow$ Nerve conduction velocity is measured on right arm from elbow to wrist, and normal range of motor nerve conduction velocity (MCV) and sensory nerve conduction velocity (SCV) are over $45 \mathrm{~m} / \mathrm{sec}$, respectively.

$\ddagger$ n.e., not evoked; $\downarrow$, decreased; + , mild; + , moderate; H. severe.

For the electron microscopic observations, the nerve specimens were prepared by the following procedures: The nerve fasciculus, gently taken out just above the ankle and cut into small pieces, were fixed in ice-cold $2.5 \%$ glutaraldehyde for $2 \mathrm{hr}$. After rinsing in the $0.1 \mathrm{M}$ cacodylate buffer ( $\mathrm{pH} 7.2$ ) overnight, they were postfixed in $1 \%$ osmium tetroxide for $11 / 2 \mathrm{hr}$. Then they were embedded in Epon 812 (Luft 1961) or Maraglas 655 (Spurlock et al. 1963) and polymerized at $60^{\circ} \mathrm{C}$ for $48 \mathrm{hr}$. Ultrathin sections were obtained with a Porter Blum MT 2-B type ultramicrotome, stained with uranyl acetate and lead citrate (Reynolds 1963). They were observed and photographed by use of a Hitachi HU 12-AS electron microscope. 


\section{Results}

In transverse view of peripheral nerve fasciculi, all the subjects showed the reduction of myelinated nerve fibers and an increase in interstitial collagen fibers (Fig. 1). Most conspicuous ultrastructural changes of nerve tissues in this study were axonal degeneration; dwindling of axon diameter compared with the thickness of myelin sheaths, depletion of axoplasmic organelles and vacuolarization. Within the reduced axons an increase in neurofilaments was obvious. There often appeared the clusters of degenerated myelin debris in place of vanishing axons (Fig. 2). Deposition of electron homogeneous amorphous materials and aggregates of glycogen-like particles (about 6-10 $\mathrm{nm}$ in diameter) were noted in a few axons of both myelinated and unmyelinated nerve fibers (Fig. 3a, b).

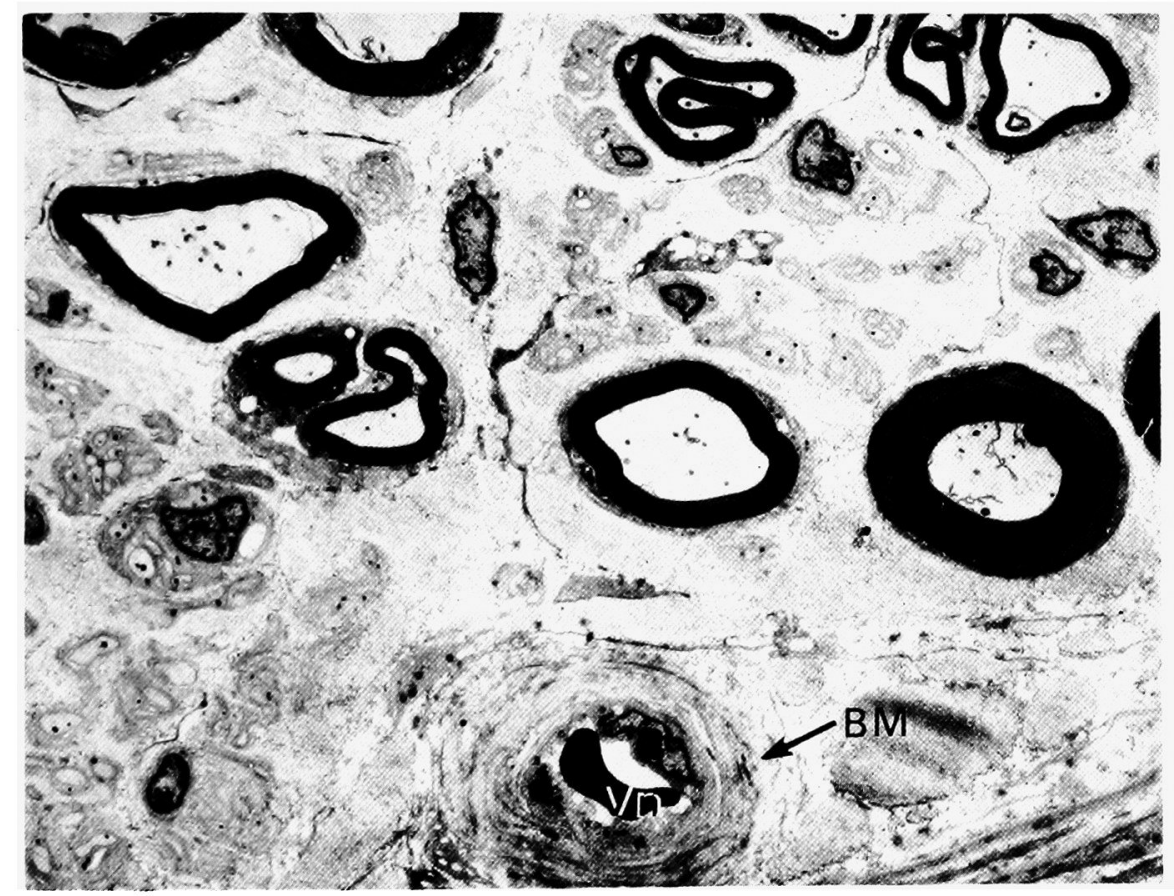

Fig. 1. Low-magnified view of a transverse section of the diabetic sural nerve in Case 1. Reduction of myelinated nerve fiber areas, some regenerated nerve fibers, splitting of myelin sheaths and an increase in interstitial collagen fibers were seen. Note the multiplication and the thickening of basement membrane (BM) of vasa nervorum (Vn). $\times 3,200$.

Destruction of myelin sheaths was also common. Between the split parts of lamellar arrangement of myelin sheaths were fine granules and degenerated myelin debris (Fig. 4). Axonal dwindling was almost always associated with deranged myelin sheaths. There also appeared clusters of several regenerated myelinated nerve fibers showing thin-lamellated myelin sheaths with more or less tortuosity. 


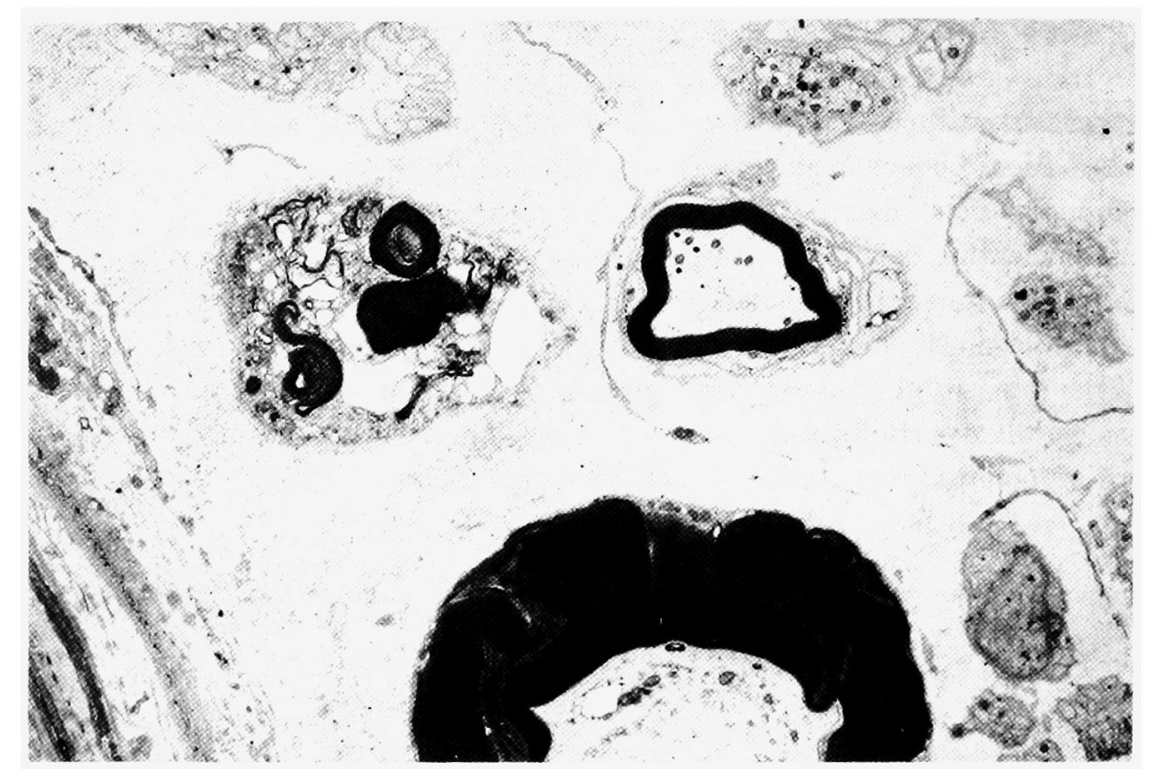

Fig. 2. Degenerated myelin debris in place of vanishing axons seen in Case 3. Myelinated nerve fibers of large diameter show an invaginated myelin sheath. $\times \mathbf{5 , 0 0 0}$.

These clusters were usually circumscribed with a layer of Schwann cell cytoplasm and its basement membrane (Fig. 5).

In the Schwann cell cytoplasm, various kinds of cytoplasmic inclusion bodies such as crystalloid bodies, lipids-like droplets and dense bodies were found (Fig. 6). Accumulation of glycogen particles in the Schwann cell cytoplasm was also prominent. Basement membranes of Schwann cells were often detached from their plasma membranes here and there and showed a ruffled elongation with thickening (Fig. 7).

Sprouting of unmyelinated nerve fibers showing multiple axons of mostly small diameter wrapped with Schwann cell cytoplasm was frequently observed. Lamellar arrangement composed of the few axons and Schwann cell cytoplasm formed the accordion-like structures. Onion bulb structures and collagen pockets formation were also found. Basement membrane of vasa nervorum showed thickening and multiplication. The mean thickness of the basement membrane of vasa nervorum in the five diabetic patients, calculated by the method of Bloodworth et al. (1969), was $12.02 \pm 3.14 \mu \mathrm{m}$, while that in normal controls was reported to be about 1-4 $\mu \mathrm{m}$ (Behse et al. 1977).

The ultrastructural changes of nerve tissues in the five diabetic patients are summarized in Table 2. The Schwann cell damage did not correlate to the axonal degeneration, and the vascular changes were also independent of either nerve fiber degeneration or degenerated Schwann cells. There was no special relationship between the nerve tissue changes and clinical symptoms or laboratory findings. 


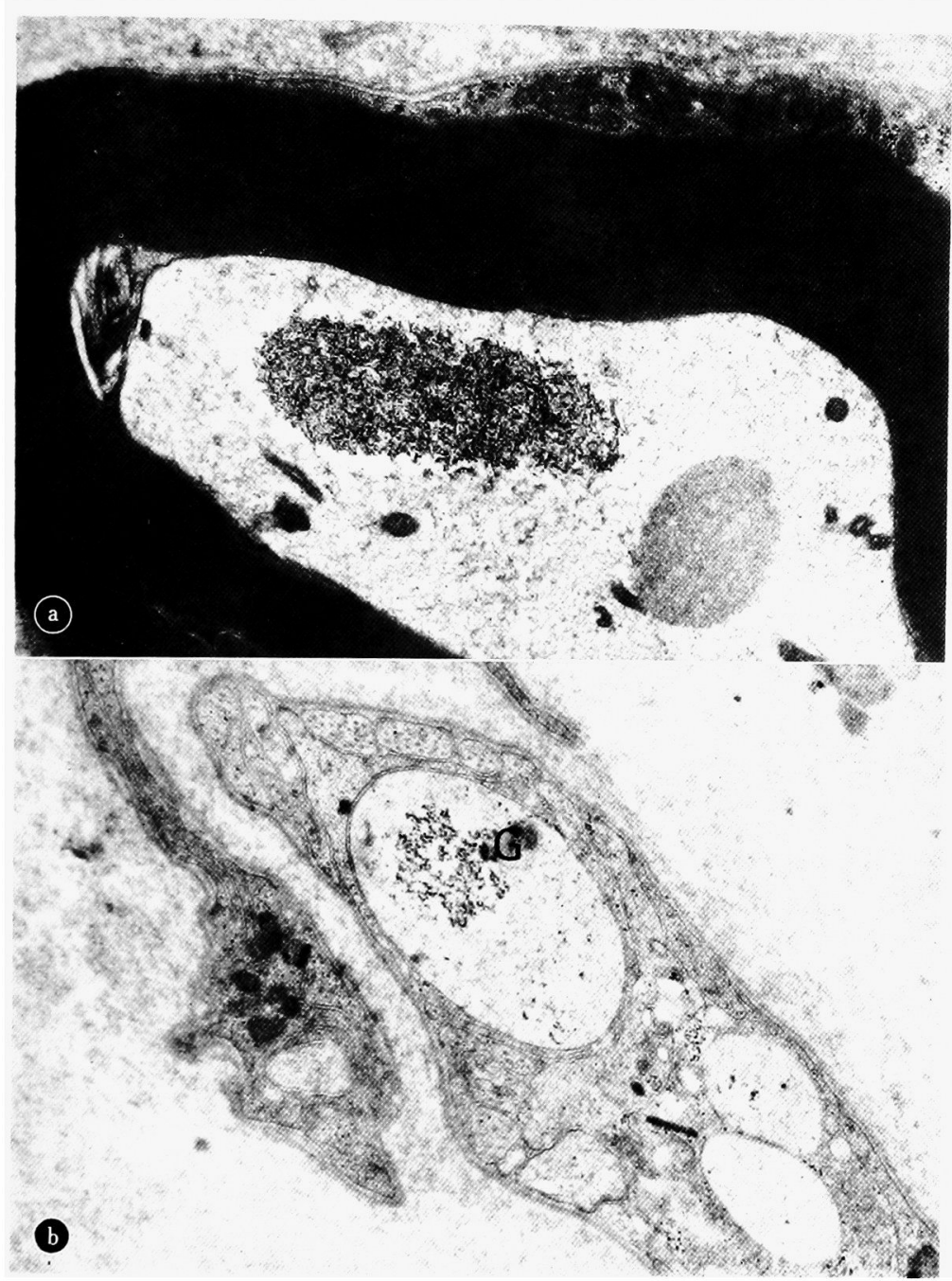

Fig. 3. a: Aggregated glycogen-like particles and electron homogeneous amorphous materials noted within the axon of a myelinated nerve fiber in Case $2 . \times 10,500$. $\mathrm{b}$ : Accumulation of glycogen-like particles $(G)$ within the axon of an unmyelinated nerve fiber in Case $2 . \times 15,000$.

\section{Discussion}

In this study, most conspicuous ultrastructural findings in diabetic sural nerves were axonal degeneration. Bischoff (1973) pointed out that the axonal degeneration showing vacuolarization and depletion of axoplasmic organelles, which resulted in the reduction of myelinated nerve fibers, was characteristic for the peripheral nerve lesions in patients with early diabetes. These figures, however, are merely degenerative changes of the axons in Wallerian degeneration or secondary changes to segmental demyelination and do not explain why the degeneration has been 


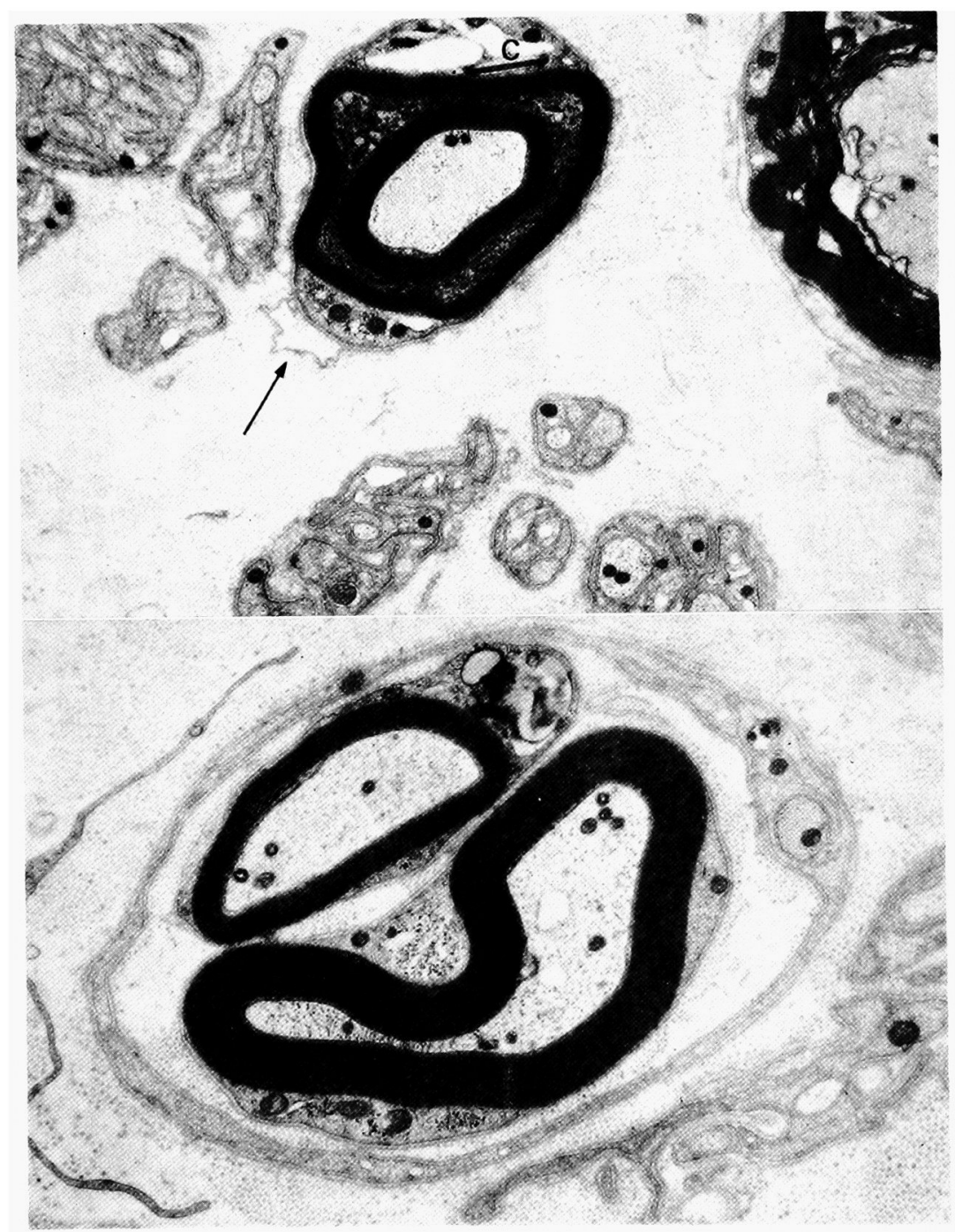

Fig. 4 (upper). Splitting of myelin sheath seen in Case 1. Between the degenerated myelin sheath, fine granules are seen. The cytoplasm of Schwann cell contains a crystalloid inclusion body (c) and its basement membrane shows ruffled elongation (arrow). $\times 9,600$.

Fig. 5 (lower). The cluster of regenerated myelinated nerve fibers encircled with a layer of Schwann cell cytoplasm and its basement membrane, seen in Case 4 . $\times 12,000$.

brought about. Basing on our observation, it allows us to consider that glycogen-like particles and electron homogeneous amorphous materials within the axons strongly suggest that metabolic abnormalities actually occur in the axons of the diabetic state. In experimental diabetic animals, accumulation of glycogen particles within mitochondria of the axons was found in the peripheral nerves of the rats rendered diabetic with alloxan for over 2 years diabetic duration (Powell et al. 1977). Biochemical study also demonstrated reduced axoplasmic flow in 


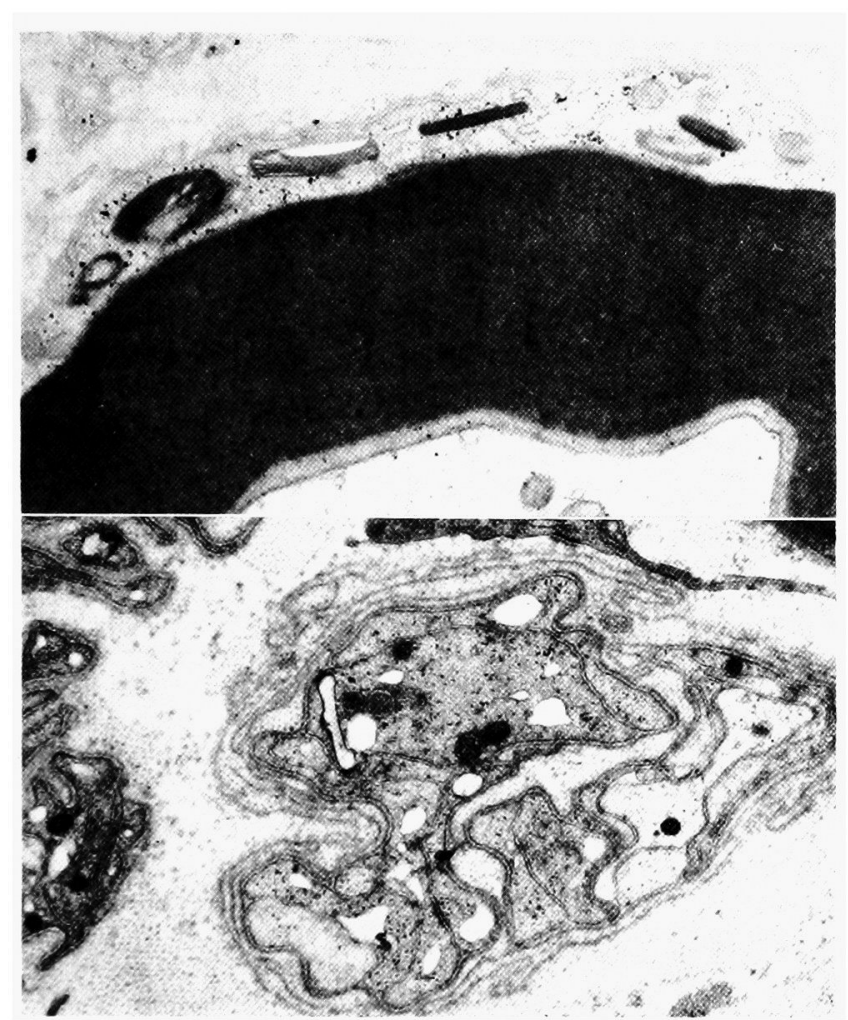

Fig. 6 (upper). Crystalloid inclusion bodies of Schwann cell cytoplasm seen in Case 3 . $\times 15,000$.

Fig. 7 (lower). Prominent basement membrane hyperplasia of Schwann cell seen in Case 4. $\times 12,000$.

experimental diabetic rats induced by streptozotocin (Schmidt et al. 1975). Recent quantitative morphological study documented that the axonal dwindling was the first abnormal sign of the peripheral nerves in early experimental diabetic rats (Jakobsen and Lundbaek 1976).

On the other hand, electron microscopic investigation of sural nerve in uremic neuropathy revealed a conspicuous axonal degeneration with accumulation of glycogen particles in the axons (Dyck et al. 1971). By teased nerve fiber studies, these patients showed prominent features of segmental demyelination that was accounted for by the secondary event of axonal degeneration (dying back neuropathy). Hence, the main structural changes in human diabetics became to be considered to be distal axonal degeneration rather than the segmental demyelination as in the case of uremic neuropathy (Dyck 1975; Brown et al. 1976), and now it has been reemphasized that diabetic neuropathy may be a neuroaxonal disorder.

As to the demyelination, in contrast to the findings of sural nerves in early diabetes (Bischoff 1973), degenerated or deranged myelin sheaths became remarkable with the evolution of peripheral nerve lesions in our patients with much 
TABLE 2. Ultrastructural findings of sural nerves in five diabetic subjects

\begin{tabular}{|c|c|c|c|c|c|}
\hline & Case 1 & Case 2 & Case 3 & Case 4 & Case 5 \\
\hline $\begin{array}{l}\text { Axonal degeneration of } \\
\text { myelinated nerve fibers }\end{array}$ & $H$ & HH & $H$ & $H$ & $H$ \\
\hline $\begin{array}{l}\text { Axonal degeneration of } \\
\text { unmyelinated nerve fibers }\end{array}$ & + & $H$ & + & + & + \\
\hline $\begin{array}{l}\text { Myelin destruction or splitting } \\
\text { of myelin sheaths of } \\
\text { myelinated nerve fibers }\end{array}$ & HH & $H$ & $H$ & $H$ & $H$ \\
\hline $\begin{array}{l}\text { Cytoplasmic changes of } \\
\text { Schwann cells }\end{array}$ & $H$ & $H$ & + & $H$ & + \\
\hline $\begin{array}{l}\text { Basement membrane hyper- } \\
\text { plasia of Sehwann cells }\end{array}$ & $H$ & $H$ & $H$ & $H$ & + \\
\hline $\begin{array}{l}\text { Multiplication and thickening } \\
\text { of basement membrane of } \\
\text { vasa nervorum }\end{array}$ & H & H & $H$ & H & \# \\
\hline $\begin{array}{l}\text { Thickness of basement } \\
\text { membrane of vasa nervorum* }\end{array}$ & $15.97 \pm 1.25$ & $10.3 \pm 1.47$ & $8.08 \pm 1.37$ & $11.47 \pm 1.19$ & $14.28 \pm 1.71$ \\
\hline
\end{tabular}

Histological findings were divided into three grades from + to $\mathrm{W}$, i.e. mild, moderate and severe, qualitatively.

* The thickness of basement membrane of vasa nervorum was estimated according to the method of Bloodworth et al. (1969), $(n==9)$.

longer diabetic duration. An earlier study by use of electron microscope (Bischoff 1968) had shown the damaged Schwann cells just as observed in our study, leading to the opinion that the diabetic neuropathy might be caused by dysmetabolism of Schwann cells. Subsequent teased nerve fiber studies (Thomas and Lascelles 1965, 1966; Chopra et al. 1969; Chopra and Fannin 1971) supported Bischoff's thesis on the basis of the observation of abundant segmental demyelination in human diabetic peripheral nerves.

Thomas and Lascelles (1966) reached their conclusion that diabetic neuropathy was Schwann cell disease and that axonal degeneration was a secondary change provoked by segmental demyelination. In our study, however, we failed to link the axonal degeneration to the damage of Schwann cells. Behse et al. (1977) have also shown that axonal degeneration and segmental demyelination proceeded independently in diabetic sural nerve lesions. When it is unsettled whether demyelination is a primary change or a secondary change to axonal degeneration in diabetic neuropathy, it is reasonable to consider that diabetic neuropathy is mainly a neuroaxonal disorder, accompanying the dysmetabolism of Schwann cells, and that these lesions develop independently.

The microangiopathy of vasa nervorum in diabetic sural nerves was constantly seen in all the diabetic subjects. Although it should not be completely neglected that microangiopathy is a primary cause of diabetic neuropathy (Fagerberg 1959; Vital et al. 1973), the nerve degeneration was inconsistent with the thickening of the vascular wall in this study. The neuropathy and microangiopathy seemed to proceed independently in the diabetic state, even if microangiopathy would influence more or less the nerve fiber degeneration. 
It has been suggested that sprouting of unmyelinated nerve fibers showing multiple axons (over 2 or 3 nerve axons) within the Schwann cell cytoplasm (type-2 fiber) were eminent in painful diabetic neuropathy (Brown et al. 1976). Our study, however, did not show any preponderance of these type-2 fibers in patients with severe spontaneous pain (Cases 3 and 4). A patient with mild sensory paresthesia (Case 1) showed more abundance of type-2 fibers. Sprouting of nerve fibers, onion bulb structures, collagen pockets or an increase in interstitial collagen fibers should be taken for merely non-specific chronic changes of peripheral neuropathy. Long term treatment with insulin or long duration of diabetic state will make complicated structural changes of the peripheral nerves. There could be found no special relationship between the ultrastructural changes of sural nerves and clinical symptoms or laboratory findings in our study. Much more subjects or precise quantitative analyses are necessary to clarify the correlation between clinical data and ultrastructural alterations of the diabetic peripheral nerve tissues.

\section{Acknowledgments}

We are very thankful to Prof. Kazunori Nagai of the First Dpt. of Pathology, Hirosaki University School of Medicine and to Prof. Yoshio Goto of the Third Dpt. of Internal Medicine, (presently, Tohoku University School of Medicine) for their thoughtful directions and advices. We also express our appreciation to Dr. S. Ohhira, S. Narita, M. Baba and K. Abe, the Third Dpt. of Internal Medicine, Hirosaki University School of Medicine for their kind cooperations in nerve biopsies.

\section{References}

1) Behse, F., Buchthal, F. \& Carlsen, F. (1977) Nerve biopsy and conduction studies in diabetic neuropathy. J. Neurol. Neurosurg. Psychiat., 40, 1072-1082.

2) Bischoff, A. (1968) Diabetische Neuropathie. Pathologische Anatomie, Pathophysiologie und Pathogenese auf Grund electronmikroskopischer Untersuchungen. Dtsch. med. Wschr., 93, 237-241.

3) Bischoff, A. (1973) Ultrastructural pathology of peripheral nervous system in early diabetes. In: Vascular and Neurological Changes in Eearly Diabetes, edited by R.A. Camerini-Davalos \& H.S. Cole, Academic Press, New York-London, pp. 441-449.

4) Bloodworth, J.M.B., Jr., Engerman, R.L., Camerini-Davalos, R.A. \& Powers, K.L. (1969) Experimental diabetic microangiopathy. 1. Basement membrane statistics in the dog. Diabetes, 18, 455-458.

5) Brown, M.J., Martin, J.R. \& Asbury, A.K. (1976) Painful diabetic neuropathy. A morphometric study. Arch. Neurol. (Chic.), 33, 164-171.

6) Chopra, J.S. \& Fannin, T. (1971) Pathology of diabetic neuropathy. J. Path. Bact., 104, $175-184$.

7) Chopra, J.S., Hurwitz, L.J. \& Montogomery, D.A.D. (1969) The pathogenesis of sural nerve changes in diabetes mellitus. Brain, 92, 391-418.

8) Dyck, P.J. (1975) Pathologic alterations of the peripheral nervous system of man. In: Peripheral Neuropathy, edited by P.J. Dyck, E.H. Lambert \& P.K. Thomas, Saunders, Philadelphia, pp. 296-336.

9) Dyck, P.J., Lambert, E.H., Sanders, K. \& O'Brien, P.C. (1971) Segmental demyelination secondary to axonal degeneration in uremic neuropathy. Mayo Clin. Proc., 46, 400-431.

10) Dyck, P.J. \& Lofgren, E.P. (1966) Method of fascicular biopsy of human peripheral nerve for electrophysiologic and histologic study. Mayo Clin. Proc., 41, 778-784. 
11) Fagerberg, S-E. (1959) Diabetic neuropathy, A clinical and histological study on the significance of vascular affections. Acta med. Scand., 345 (Suppl. 164), 1-97.

12) Goto, Y., Chiba, M. \& Maruhama, Y. (1972) Correlation between the treatment of diabetes and the diurnal curves of blood glucose levels. Shindan to Chiryo, 60, 149153. (Japanese)

13) Greenbaum, D., Richardson, P.C., Salmon, M.V. \& Urich, H. (1964) Pathologic observation on six cases of diabetic neuropathy. Brain, 87, 201-213.

14) Jakobsen, J. \& Lundbaek, K. (1976) Neuropathy in experimental diabetes: An animal model. Brit. med. J., 2, 278-279.

15) Luft, J.H. (1961) Improvements in epoxy resin embedding methods. J. biophysic. biochem. Cytol., 9, 409-414.

16) Powell, H., Knox, D., Lee, S., Charters, A.C., Orloff, M., Garrett, R. \& Lampert, P. (1977) Alloxan diabetic neuropathy: Electron microscopic studies. Neurology (Minneap.), 27, 60-66.

17) Reynolds, E.S. (1963) The use of lead citrate at high pH as an electron-opaque stain in electron microscopy. J. Cell Biol., 17, 208-213.

18) Schmidt, R.E., Matschinsky, F.M., Godfrey, D.A., Williams, A.D. \& McDougal, D.B., Jr. (1975) Fast and slow axoplasmic flow in sciatic nerve of diabetic rats. Diabetes, 24, 1081-1085.

19) Spurlock, B.O., Kattine, V.C. \& Freeman, J.A. (1963) Technical modifications in Maraglas embedding. J. Cell. Biol., 17, 203-207.

20) Thomas, P.K. \& Lascelles, R.G. (1965) Schwann-cell abnormalities in diabetic neuropathy. Lancet, 1, 1355-1356.

21) Thomas, P.K. \& Lascelles, R.G. (1966) The pathology of diabetic neuropathy. Quart. J. Med., 35, 489-509.

22) Vital, Cl., Vallat, J.M., LeBlane, M., Martin, F. \& Coquet, M. (1973) Les neuropathies peripheriques du diabete sucre. Etude ultrastructurale de 12-cas biopsies. $J$. neurol. Sci., 18, 381-398. 